\title{
Catechin prevents the calcium oxalate monohydrate induced renal calcium crystallization in NRK-52E cells and the ethylene glycol induced renal stone formation in rat
}

\author{
Wei Zhai, Junhua Zheng, Xudong Yao, Bo Peng, Min Liu, Jianhua Huang, Guangchun Wang and Yunfei Xu
}

\begin{abstract}
Background: Reactive oxygen species play important roles in renal calcium crystallization. In this study, we examined the effects of catechin, which have been shown to have antioxidant properties on the renal calcium crystallization.
\end{abstract}

Methods: In the vitro experiment, the changes of the mitochondrial membrane potential, expression of superoxide dismutase (SOD), 4-hydroxynonenal (4-HNE), cytochrome c, and cleaved caspase 3 were measured to show the effects of catechin treatment on the NRK-52E cells induced by calcium oxalate monohydrate (COM). In the vivo study, Sprague-Dawley rats were administered 1\% ethylene glycol (EG) to generate a rat kidney stone model and then treated with catechin ( 2.5 and $10 \mathrm{mg} / \mathrm{kg} /$ day) for 14 days. The urine and serum variables were dected on 7 and 14 days after EG administration. The expression of cytochrome c, cleaved caspase 3, SOD, osteopontin (OPN), malondialdehyde (MDA), 8-hydroxy-2'-deoxyguanosine (8-OHdG) in kidney were measured. Furthermore, the mitochondrial microstructure in the kidney was also examined by transmission electron microscopy.

Results: Catechin treatment could prevent the changes in mitochondrial membrane potential and expression of SOD, 4-HNE, cytochrome c, and cleaved caspase 3 in NRK-52E cells induced by the COM. For the in vivo experiments, the EG administration induced renal calcium crystallization was also prevented by the catechin. The expression of SOD, OPN, MDA, OPN and 8-OHdG, were increased after EG administration and this increase was diminished by catechin. Moreover, catechin also prevented EG induced mitochondrial collapse in rat.

Conclusions: Catechin has preventive effects on renal calcium crystallization both in vivo and in vitro, and provide a potential therapeutic treatment for this disease.

Keywords: Renal tubular cell injury, Renal calcium crystallization, Catechin, In vivo, In vitro

\section{Background}

Nephrolithiasis is the condition marked by the development of renal stones. Renal stones are aggregates of crystals that are formed in supersaturated urine [1]. Calcium oxalate may occur as multiple stones or may recur, can induce pain with both passage and obstruction, and is commonly caused by treatable metabolic disorders of hypercalciuria [2]. It appears as a complex disease that may develop change-able clinical manifestations [3].

\footnotetext{
* Correspondence: jacky_zw2002@hotmail.com

Department of Urology, Shanghai Tenth People's Hospital, Tongji University School of Medicine, Shanghai 200072, China
}

Despite the increasing prevalence of the disease in China, little research is available for indicating the mechanism and prophylaxis for renal calculus in detail.

It has already known that exposure to high levels of oxalate and calcium oxalate crystals can induce oxidative stress such as an increase in free radical generation, increased lipid peroxidation, a decrease in cellular antioxidant status and an increase in phospholipase-A2 (PLA2)-induced release of arachidonic acid [4-6]. Sustained exposure to high levels of oxalate or calcium oxalate crystals injures the cells [7]. Mitochondria have been demonstrated to show excessive uptake of calcium 
when the cytoplasm level of free calcium markedly increases, causing abnormalities in the respiratory chain and increasing the mitochondrial production of ROS (Reactive Oxygen Species) [8,9]. Calcium-induced mitochondrial injury can be prevented by antioxidants suggesting that oxidative stress may be an important event in its development [8].

Renal tubular cell injury is induced by the oxidative stress, which is produced during the attachment of crystals to renal tubular cells [10]. Exposure to high concentrations of oxalate can give rise to the generation of ROS, mitochondrial collapse and increased lipid peroxidation, which induces the cell death in cultured renal epithelial cells $[11,12]$. Renal toxicity is assumed to be caused by the elevation of serum-free iron concentration, following its reduction at the luminal side of the proximal tubule, which generates ROS decreasing antioxidant systems and also leads to the enhancement in lipid peroxidation $[13,14]$. It has been demonstrate that toxic action of acephate on kidney cells is partly through an ROS-mediated mechanism [15]. And ROS are known to mediate many toxin induced renal tubular injuries [16-18].

In renal tubular cell injury, mitochondrial damage has been recognized as a crucial cause for tubular cell death which involves disruption of respiration complexes and loss of mitochondrial membrane potential $[19,20]$. And cell apoptosis is precipitated by mitochondrial outer membrane permeabilization and consequent release of apoptogenic factors such as cytochrome c [21]. Caspases are crucial mediators of programmed cell death (apoptosis). Among them, caspase-3 is a frequently activated death protease, catalyzing the specific cleavage of many key cellular proteins [22]. Caspase-3 is activated in the apoptotic cell both by extrinsic (death ligand) and intrinsic (mitochondrial) pathways [23,24]. In intrinsic activation, cytochrome $\mathrm{c}$ from the mitochondria works in combination with caspase-9, apoptosis-activating factor 1 (Apaf-1), and ATP to process procaspase-3 [22,25,26].

Catechin, regarded as one of the main components of green tea, is considered to exert antioxidant effects acting directly as radical scavengers or metal-chelators and also indirectly through modulation of transcription factors or enzymes $[27,28]$. As ROS plays an important role in renal calcium crystallization, catechin may have the therapeutic effect.

Therefore, we administered catechins to renal proximal tubular cell and rats with stone formation to investigate its inhibitory effects on urolithiasis. In this study, we examined the changes in oxidative stress in an in vitro study and in vivo study. We further showed that renal calcium crystallization was significantly decreased by catechin treatment. Together, these results provide compelling evidence for a role of oxidative stress, which activates the initial process of renal calcium crystallization and can be prevented by catechin.

\section{Methods}

\section{Preparation of calcium oxalate monohydrate (COM)} crystal suspensions

Oxalic acid $(200 \mathrm{mM}, 0.5 \mathrm{ml})$ and $200 \mathrm{mM}$ calcium chloride we remixed at room temperature to a final concentration of $10 \mathrm{mM}$, and the COM crystals that immediately formed in suspension were equilibrated for 3 days. The COM crystals were then washed three times with sodium and chloride-free distilled water saturated with calcium oxalate, resuspended to a final concentration of $2.92 \mathrm{mg} / \mathrm{ml}$, and adjusted to $\mathrm{pH} 6.8$.

\section{Cell culture}

The renal proximal tubular cell line NRK-52E (the Type Culture Collection of the Chinese Academy of Sciences, Shanghai, China.) was cultured in Dulbecco's modified Eagle's medium (GIBCO, USA) and was supplemented with $10 \%$ newborn calf serum,100 $\mathrm{IU} / \mathrm{ml}$ penicillin, and $100 \mu \mathrm{g} / \mathrm{ml}$ streptomycin (Life Technologies, Burlingont, ONT, Canada). The cells were routinely seeded at a density of $1 \times 10^{6} / 60$-mm culture dish (Corning Incorporated, Glendale, Arizona, United States) at $37^{\circ} \mathrm{C}$ in a humidified atmosphere of $5 \% \mathrm{CO}_{2}$ in air. The medium was changed every three day and the cells were subcultured before forming confluent monolayers.

NRK-52E cells were seeded at a density of $1 \times 10^{6} /$ 90-mm dish and cultured to $90 \%$ confluence. The cells were then treated with or with-out catechin hydrate (Beyotime Biotechnology, Haimen, Jiangsu, China) $(0.4 \mu \mathrm{l} / \mathrm{ml})$ for $10 \mathrm{~min}$ and then with COM crystals $\left(80 \mu \mathrm{g} / \mathrm{cm}^{2}\right)$. In our study, cell suspension was prepared and counted in the blood counting chamber.

\section{Measurement of mitochondrial membrane potential $(\Delta \psi \mathrm{m})$}

Cells were loaded with the membrane potential-sensitive dye tetramethylrhodamine ethyl ester perchlorate (TMRE; $20 \mathrm{nM}$ in Hepes-buffered salt solution; Invitrogen, Carlsbad, CA, USA). Cells loaded with TMRE were then analyzed using a confocal micro-scope (LSM5 PASCAL; Carl Zeiss Co. Ltd., Oberkochen, Germany) equipped with $\times 20$ and $\times 100$ oil-immersion, quartz objective lenses. The cells were then treated with or without CsA (Cyclosporin A, $2 \mu \mathrm{M}$ ) for $10 \mathrm{~min}$ and then with COM crystals $(100 \mu \mathrm{g} / \mathrm{cm} 2)$ for $0,5,10,15$, and $30 \mathrm{~min}$. As a negative control, untreated NRK-52E cells were ob-served, and as a positive control, we used carbonyl cyanide m-chlorophenyl hydrazone (CCCP; $10 \mu \mathrm{M}$ ), an uncoupler that causes mitochondrial depolarization. Mitochondrial fidelity in cells stained with TMRE was quantified by flow cytometry. After three 
washes with phosphate-buffered saline (PBS) to remove COM crystals, stained cells in each group were detached using $0.05 \%$ trypsin - EDTA (Ethylene Diamine Tetraacetic Acid), washed with PBS, and diluted to $1 \mathrm{ml}$. A total of 30,000 events were collected from each sample and the data were displayed on a logarithmic scale of increasing red fluorescence intensity using a FACS Calibur HG (Becton-Dickinson, Franklin Lakes, NJ, USA).

\section{Experimental animals}

All experimental procedures were performed with the approval of the Animal Care Committee of the Faculty of Medicine, Tongji University. Male Sprague-Dawley (SD) rats (Charles River Japan, Yokohama, Japan), age 7 weeks weighing approximately $280 \mathrm{~g}$ were used. Animals were provided with a standard $\mathrm{mEq}$ diet (containing calcium, $1.12 \mathrm{~g}$; phosphorus, $0.9 \mathrm{~g}$; magnesium, $0.26 \mathrm{~g}$; and sodium, $0.21 \mathrm{~g} / 100 \mathrm{~g}$; Oriental Yeast Co., Tokyo, Japan) and free access to water. To induce calcium oxalate deposition in the kidneys rats were given 2 doses of $0.12 \mathrm{ml} \mathrm{5 \%}$ ethylene glycol (EG) (Wako, Tokyo, Japan) and then treated twice per day with catechin through a stomach tube. The rats were assigned to one of the following groups ( $\mathrm{n}=10$ per group) and weighed weekly: one group received EG only (EG group) and two EG and catechin groups also received 2.5 and $10 \mathrm{mg} / \mathrm{kg} /$ day catechin (EG + catechin 2.5, EG + catechin 10.0 groups, respectively). At 7 and 14 days after the start of drug therapy, blood was sampled from the inferior vena cave of 5 rats per group. These rats were sacrificed under ether anesthesia and both kidneys were immediately excised and dissected. One kidney was histologically examined and RNA was extracted from the other. Two days before euthanasia, the rats were placed individually in metabolic cages for $24 \mathrm{~h}$ and urine samples were collected into cups containing $\mathrm{HCl}$ for oxalate measurements. The kidneys and urine samples were obtained from control rats without EG or catechin at day $0(n=5)$.

\section{Western blotting}

NRK-52E cells stored at $-20^{\circ} \mathrm{C}$ were immersed in $1 \times$ lysis buffer and lysed by sonication on ice. The total protein concentration in the supernatant was spectrophotometrically quantified using an Ultrospec 3100 Pro (GE Healthcare, Wallingford, CT, USA). Samples containing $30 \mu \mathrm{g}$ total protein were mixed with loading buffer (Laemmli sample buffer; Bio-Rad Laboratories, Hercules, CA, USA).

Proteins were resolved by $12.5 \%$ sodium dodecyl sulfate-polyacryl-amide gel electrophoresis and transferred onto Immobilonpolyviny-lidene fluoride membranes (Millipore, Bedford, MA, USA). Blocking for $1 \mathrm{~h}$ at room temperature was followed by an overnight incubation with one of the following antibody: anti-rat malondialdehyde (MDA) antibody, anti-rat 8-hydroxy-2'deoxyguanosine (8-OHdG) antibody, polyclonal anti-rat superoxide dismutase (SOD) antibody (dilution 1:100; Santa Cruz Biotechnology, Santa Cruz, CA, USA), antirat 4-hydroxy-2-nonenal (4-HNE) monoclonal antibody (dilution 1:4; Nikken Seil, Shizuoka, Japan), and anti-rat cleaved caspase 3 antibody (dilution 1:1000; Cell Signaling Technology, Beverly, MA, USA) at $4^{\circ} \mathrm{C}$. After being washed, the membranes were treated with the corresponding peroxidase-conjugated secondary antibodies for $1 \mathrm{~h}$ at room temperature. Proteins were visualized using enhanced chemiluminescence Western blotting analysis kits (PierceBiotechnology). The membranes were probed with a $\beta$-actin anti-body as a loading control (Sigma - Aldrich, St. Louis, MO, USA). For Western blotting of cytochrome c, a similar procedure was followed except for the use of samples (cytosol fraction isolated from NRK-52E cells) containing $10 \mu \mathrm{g}$ total protein and anti-rat cytochrome c antibody (dilution 1:1000; Cell Signaling Technology).

The same membrane was used for catechin (-) COM $(+)$ and catechin $(+) \mathrm{COM}(+)$ group to ensure uniformity. The protein expression levels in the bands corresponding to SOD, 4-HNE, cytochrome c, and cleaved caspase $3 \quad(n=5$ each $)$ were quantified using Image Quant LAS 4000 (GE Healthcare Japan, Tokyo, Japan), which is a multipurpose CCD (Charge Coupled Device) camera system for quantitative imaging of blots developed by Amersham for enhanced chemiluminescence, with standard UV (ultraviolet) transillumination for ethidium bromide gel visualization.

\section{Measurement of urinary and serum variables}

Urinary volume and urinary $\mathrm{pH}$ were measured manually. Urinary calcium and serum creatinine, serum calciumwere determined using an automated analyzer (Model 705, Hitachi, Tokyo, Japan). Urinary oxalate was determined using oxalate decarboxylase and citrate was determined by citrate lyase conversions to oxaloacetate.

\section{Transmission electron microscopy (TEM)}

The microstructure of mitochondria in the kidney was examined using TEM. Kidneys were perfusion- fixed using $20 \mathrm{ml}$ of $0.1 \mathrm{M}$ phosphoric acid buffer and $20 \mathrm{ml}$ of $2.5 \%$ glutaraldehyde, extracted and washed with phosphoric acid buffer, and then fixed with $2 \%$ osmium tetraoxide for $2 \mathrm{~h}$. Tissues were dehydrated using a graded series of ethanol (50- 100\%), embedded in epoxy resin, and polymerized at $60^{\circ} \mathrm{C}$ for $48 \mathrm{~h}$. The ultrathin sections $(99 \mathrm{~nm})$ were double stained with uranium and lead for observation using a JEM-1011 TEM microscope (JEOL Ltd., Tokyo, Japan). 


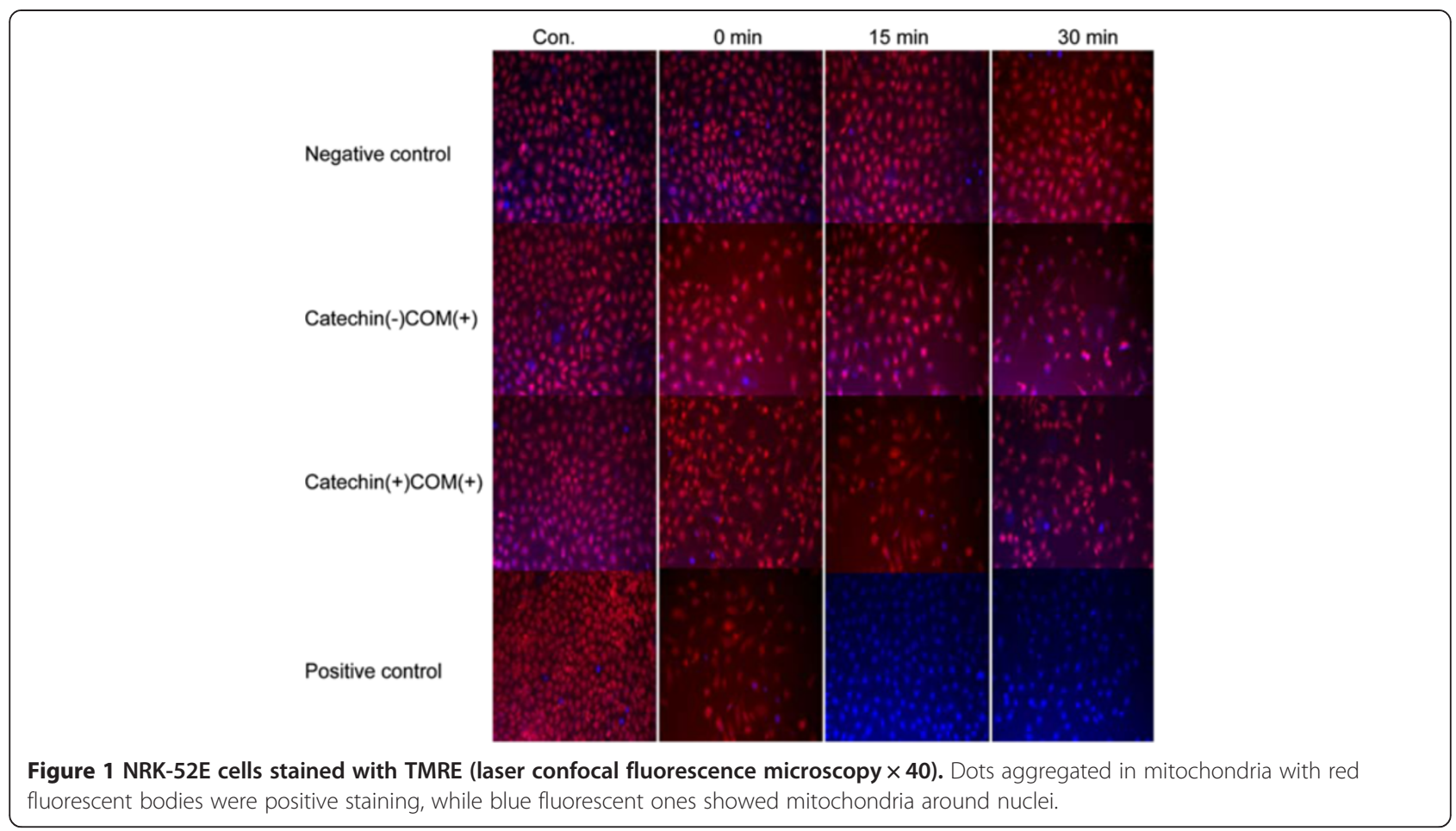

\section{Statistical analysis}

All data are expressed as means \pm standard deviation. The statistical significance of differences among groups was examined using the Mann-Whitney U test. A $\mathrm{P}$ value of $<0.05$ denotes a statistically significant difference.

\section{Results}

Changes in mitochondrial membrane potential in NRK-52E cells exposed to COM or COM\&catechin

NRK-52E cells stained with TMRE, which are aggregated in mitochondria with red fluorescent bodies, while blue fluorescent ones show mitochondria around nuclei (Figure 1). The negative control cells indicated no change in TMRE intensity from $0 \mathrm{~min}$ to $30 \mathrm{~min}$. The TMRE intensity of catechin (-) COM (+) cells exposed to COM crystals gradually decreased during $0 \mathrm{~min}$ to $30 \mathrm{~min}$. On the other hand, red fluorescent bodies in catechin (+) COM (+) cells exposed to both catechin and COM crystals had no significant change from $0 \mathrm{~min}$ to $30 \mathrm{~min}$. In the positive control, TMRE intensity completely disappeared within $15 \mathrm{~min}$ and $30 \mathrm{~min}$.

Form the results of flow cytometry, the peak TMRE intensity of catechin (-) COM (+) cells was shifted to the left at $15 \mathrm{~min}$ and shifted slightly more to the left at $30 \mathrm{~min}$, compared to that of the catechin (-) COM (+) cells at $0 \mathrm{~min}$ (Figure 2A). However, in catechin $(+)$ COM (+) cells, the shift in peak TMRE intensity was negligible during $0 \mathrm{~min}$ to $30 \mathrm{~min}$ (Figure 2B).
Expression changes of SOD, 4-HNE, cytochrome $\mathrm{c}$ and cleaved caspase 3 in NRK-52E cells exposed to COM or COM\&catechin

In catechin (-) COM (+) cells, SOD expression decreased gradually in a time-dependent manner, whereas no significant changes were detected in catechin $(+)$ COM $(+)$ cells (Figure 3A). There were obviously differences in the expression of SOD between catechin (-) COM (+) cells and catechin $(+) \operatorname{COM}(+)$ cells at 1,3 , and $6 \mathrm{~h}$ after exposure to COM crystals $(\mathrm{P}<0.05$, Figure 3C).

Meanwhile, the expression of 4-HNE increased gradually from $0 \mathrm{~min}$ to $6 \mathrm{~h}$ in catechin (-) COM (+) cells,
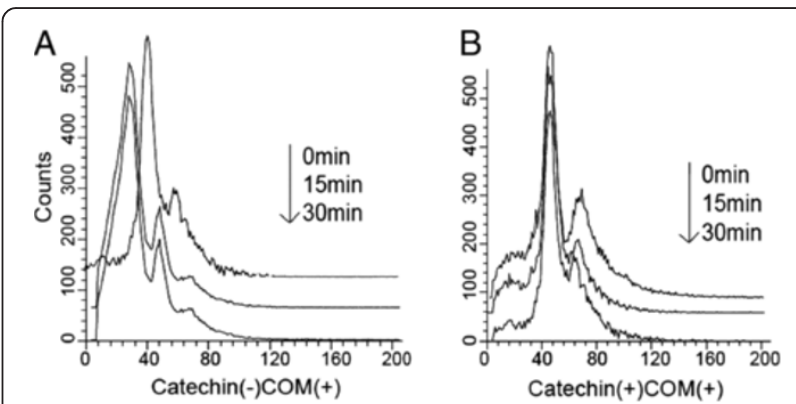

Figure 2 The results of flow cytometry of NRK-52E cells stained with TMRE. The COM treated NRK-52E cells without catechin administration is shown as (A). NRK-52E cells treated with both COM and catechin were shown as (B). The assays were carried out at 0,15 and $30 \mathrm{~min}$ 


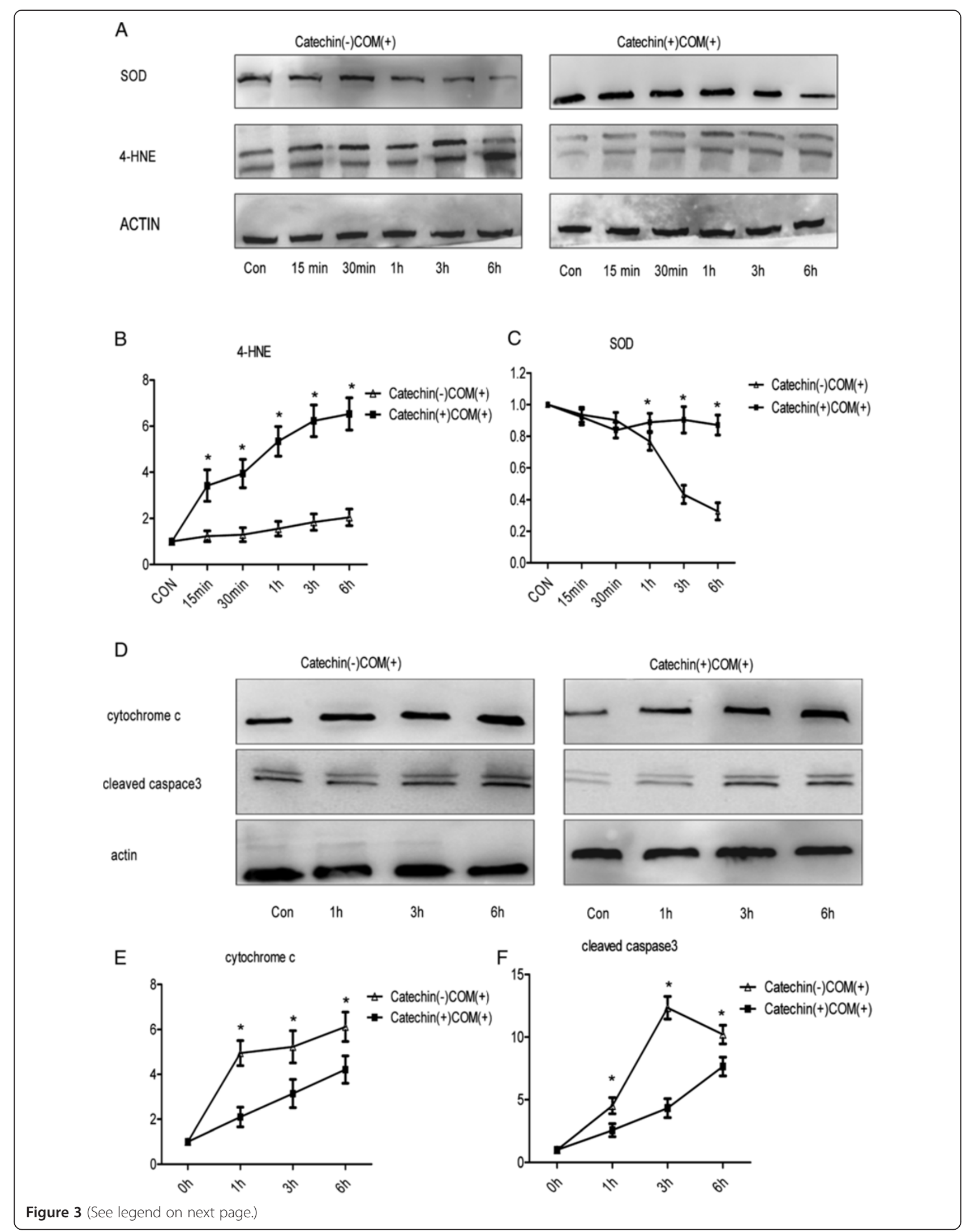


(See figure on previous page.)

Figure 3 The expression of superoxide dismutase (SOD), 4-hydroxynonenal (4-HNE), cytochromec, and cleaved caspase 3. Proteins were subjected to Western blotting using antibodies against SOD, 4-HNE (A) cytochrome C, and cleaved caspase 3 (D) and quantified by densitometric scanning, results being expressed in arbitrary units. Figure (B) and (C) present the expression of SOD, 4-HNE, while (E) and (F) for Cytochrome C, and cleaved caspase 3. Values are the mean \pm SEM for five independent determinations. *Statistically significant difference $(P<0.05)$, catechin $(-)$ $\operatorname{COM}(+)$ vs. catechin (+) $\operatorname{COM}(+)$.

however, it was a gentle increase in catechin $(+) \mathrm{COM}$ $(+)$ cells (Figure 3A). The change of 4-HNE expression between catechin $(-)$ COM $(+)$ cells and catechin $(+)$ $\mathrm{COM}(+)$ cells was significantly observed at $15 \mathrm{~min}$, $30 \mathrm{~min}, 1 \mathrm{~h}, 3 \mathrm{~h}$ and $6 \mathrm{~h}$ after exposure to COM crystals $(\mathrm{P}<0.05$, Figure $3 \mathrm{~B})$.

For the expression of cytochrome c, in catechin $(+)$ $\mathrm{COM}(+)$ cells, the expression increased at $1 \mathrm{~h}, 3 \mathrm{~h}$, and $6 \mathrm{~h}$ after exposure to $\mathrm{COM}$ crystals, but the expression was lower than that in catechin $(-) \mathrm{COM}(+)$ cells (Figure 3D). The change of cytochrome c expression between catechin $(-)$ COM $(+)$ cells and catechin $(+)$ COM (+) cells was significantly observed at $1 \mathrm{~h}, 3 \mathrm{~h}$, and $6 \mathrm{~h}$ after exposure to COM crystals $(\mathrm{P}<0.05$, Figure $3 \mathrm{E})$.

The expression of cleaved caspase 3 was increased from $0 \mathrm{~h}$ to $6 \mathrm{~h}$ in catechin (+) COM (+) cells. The expression of cleaved caspase 3 increased from $0 \mathrm{~h}$ to $3 \mathrm{~h}$ whereas reduced from $3 \mathrm{~h}$ to $6 \mathrm{~h}$ in catechin (-) COM $(+)$ cells (Figure 3D). There were significant differences in the expression of cleaved caspase 3 between catechin $(-)$ COM (+) cells and catechin (+) COM (+) cells at $1 \mathrm{~h}$, $3 \mathrm{~h}$ and $6 \mathrm{~h}$ after exposure to COM crystals $(\mathrm{P}<0.05$, Figure $3 \mathrm{~F})$.

\section{Urinary and serum variables in the control and crystal-model rat}

There were no changes in urine volume or urinary $\mathrm{pH}$ on 7 and 14 days after EG administration. In the EG group, urine volume was significantly lower than in the EG + catechin10.0 group on 14 days. In the EG group, 24-hour urine oxalate excretion was significantly higher than in the control group after administration $(\mathrm{P}<0.05)$. The 24-hour urine oxalate of EG + catechin2.5 group was more than 5.6-fold and 8.7-fold higher than that of the control group on 7 and 14 days, respectively. The 24-hour urine oxalate of EG + catechin 10.0 group was more than 6.4-fold and 8.2-fold higher than that of the control group on 7 and 14 days, respectively $(\mathrm{P}<0.05$, Table 1).

On the other hand, there were no significant differences in 24-hour urine calcium among the control group, the EG group and the EG + catechin groups. Meanwhile, there were no marked differences in serum creatinine and calcium levels among the control, EG, and EG + catechin groups on 7 and 14 days after administration $(\mathrm{P}>0.05$, Table 1$)$.

\section{Immunohistochemical staining for SOD, osteopontin, MDA and 8-OHdG in the control and crystal-model rat kidneys}

Strong expression of SOD could be observed in the control group, but SOD was not detected in EG group. The expression of SOD was slightly lower in EG + catechin 2.5 group than that in EG + catechin10.0 group (Figure 4).

Osteopontin (OPN) was also tested by immunohistochemical staining. OPN was barely detectable in the

Table 1 The results of the measurement of urinary and serum variables

\begin{tabular}{|c|c|c|c|c|c|c|}
\hline \multirow[t]{2}{*}{ Group (day) } & \multirow{2}{*}{$\begin{array}{c}\text { Urine } \\
\text { volume (ml) }\end{array}$} & \multirow[t]{2}{*}{ Urinary $\mathrm{PH}$} & \multicolumn{2}{|c|}{ Urine (mg/day) } & \multicolumn{2}{|c|}{ Serum (mg/dl) } \\
\hline & & & Oxalate & Calcium & Creatinine & Calcium \\
\hline \multicolumn{7}{|l|}{ Control } \\
\hline 7 & $17.54 \pm 3.7$ & $8.36 \pm 0.3$ & $1.88 \pm 0.3$ & $3.4 \pm 1.09$ & $0.22 \pm 0.05$ & $10.83 \pm 0.47$ \\
\hline 14 & $17.04 \pm 4.9$ & $8.49 \pm 0.7$ & $1.77 \pm 0.5$ & $3.45 \pm 2.46$ & $0.23 \pm 0.08$ & $11.29 \pm 0.85$ \\
\hline \multicolumn{7}{|l|}{ EG } \\
\hline 7 & $16.54 \pm 6.6$ & $8.44 \pm 1.3$ & $13.57 \pm 1.5^{*}$ & $4.13 \pm 0.87$ & $0.28 \pm 0.12$ & $11.52 \pm 0.23$ \\
\hline 14 & $16.05 \pm 7.5$ & $8.85 \pm 0.5$ & $13.58 \pm 1.3^{*}$ & $3.87 \pm 1.12$ & $0.36 \pm 0.13$ & $10.50 \pm 0.13$ \\
\hline \multicolumn{7}{|c|}{ EG + catechin 2.5} \\
\hline 7 & $21.28 \pm 1.7$ & $8.76 \pm 0.7$ & $10.55 \pm 1.1^{*}$ & $3.23 \pm 0.45$ & $0.26 \pm 0.09$ & $11.06 \pm 0.45$ \\
\hline 14 & $22.01 \pm 4.8$ & $8.55 \pm 2.1$ & $15.46 \pm 0.9^{*}$ & $3.73 \pm 0.68$ & $0.27 \pm 0.05$ & $11.01 \pm 0.43$ \\
\hline \multicolumn{7}{|c|}{$\mathrm{EG}+$ catechin 10.0} \\
\hline 7 & $19.32 \pm 2.4$ & $8.56 \pm 0.7$ & $12.05 \pm 1.3^{*}$ & $4.65 \pm 1.32$ & $0.20 \pm 0.04$ & $11.07 \pm 0.36$ \\
\hline 14 & $27.05 \pm 7.5$ & $8.77 \pm 1.4$ & $14.53 \pm 2.4^{*}$ & $4.14 \pm 1.78$ & $0.23 \pm 0.06$ & $11.21 \pm 0.43$ \\
\hline
\end{tabular}

The statistical significance of differences among groups was examined using the Mann-Whitney $U$ test. ${ }^{*}, P<0.05$. 


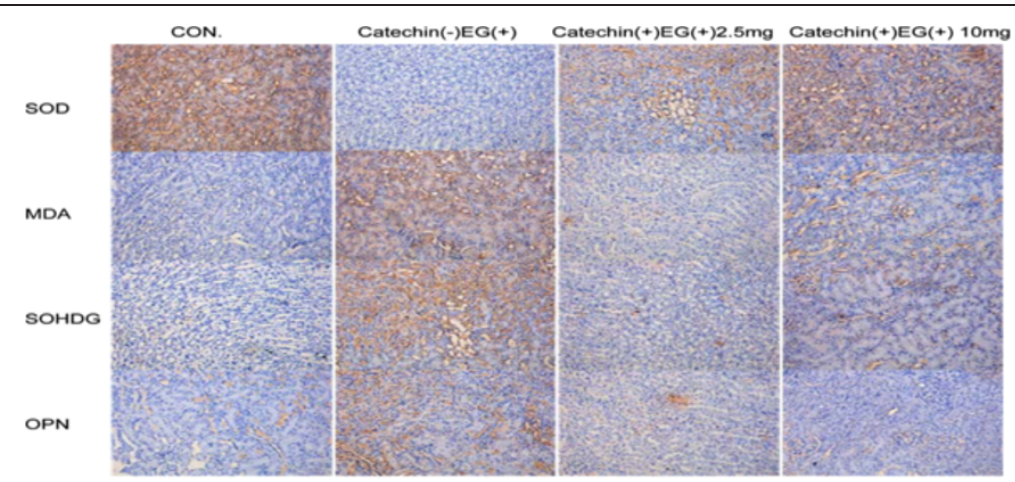

Figure 4 Th immunohistochemical staining of superoxide dismutase (SOD), malondialdehyde (MDA), 8-hydroxy-2'-deoxyguanosine (8-OHdG), and osteopontin (OPN) in the kidney of the rat on day 14. All the images represent serial sections. EG, EG + catechin2.5, EG + catechin 10.0 represent rats administered with EG or EG and catechin at $0,2.5$, and $10.0 \mathrm{mg} / \mathrm{kg} /$ day, respectively. Strong expression of SOD was could be observed in the control group, but SOD was not detected in EG group. The expression of SOD was slightly lower in EG + catechin 2.5 group than that in EG + catechin10.0 group. OPN was barely detectable in the control group, but it was strongly expressed in the EG group. The OPN expression in EG + catechin2.5 group was slightly higher than that in EG + catechin10.0 group. MDA was undetectable in the control group and EG + catechin groups, but it was detectable in EG group kidneys. The expression of 8-OHdG was undetectable in the control group, but it was detectable in the EG group. And the expression of 8-OHdG was nearly undetectable in the EG + catechin groups.

control group, but it was densely distributed throughout the renal tubular cells of whole kidneys in the EG group. OPN expression was slightly higher in EG + catechin2.5 group than in EG + catechin10.0 group (Figure 4).

MDA was undetectable in the renal tubular cells of whole kidneys in the control group, but it was detectable in EG group kidneys. In the EG + catechin groups, MDA production was undetectable (Figure 4).

Similarly, the expression of 8-OHdG was undetectable in the renal tubular cells of whole kidneys in the control group, but it was detectable in the nuclei of renal tubular cells of whole kidneys in the EG group. In the EG + catechin groups, the expression of $8-\mathrm{OHdG}$ was nearly undetectable (Figure 4).

Finally, the ratios of the OPN, MDA and 8-OHdG expression areas were significantly higher in the EG group than those in the other groups $(\mathrm{P}<0.05$, Figure 5$)$. Meanwhile, there was no significant difference in the ratios of SOD, OPN, MDA and 8-OhdG expression areas among the control group, EG + catechin 2.5 group and $\mathrm{EG}+$ catechin 10.0 group $(\mathrm{P}>0.05$, Figure 5$)$.

\section{OPN, cytochrome c and cleaved caspase 3 expression} changes evaluated by western bolting in the control and crystal-model rat

OPN expression increased gradually after EG treatment in rat. In EG + catechin 2.5 group and EG + catechin 10.0 group, the expression of OPN was higher than that in EG group $(\mathrm{P}<0.05)$. Additionally, administration of catechin after EG treatment enhanced the expression of OPN. There was a significant change in OPN expression between the control and EG group. A significant differences between EG group and EG + catechin groups were also observed ( $\mathrm{P}<0.05$, Figure 6).

The expression of cytochrome $\mathrm{c}$ had no changes among the four groups. There was a significant change in cleaved caspase 3 between the control and EG + catechin 2.5 group $(\mathrm{P}<0.05)$. There were no significant differences among the other three groups for the expression of cleaved caspase 3 in crystal-model rat kidneys $(P>0.05$, Figure 6$)$.

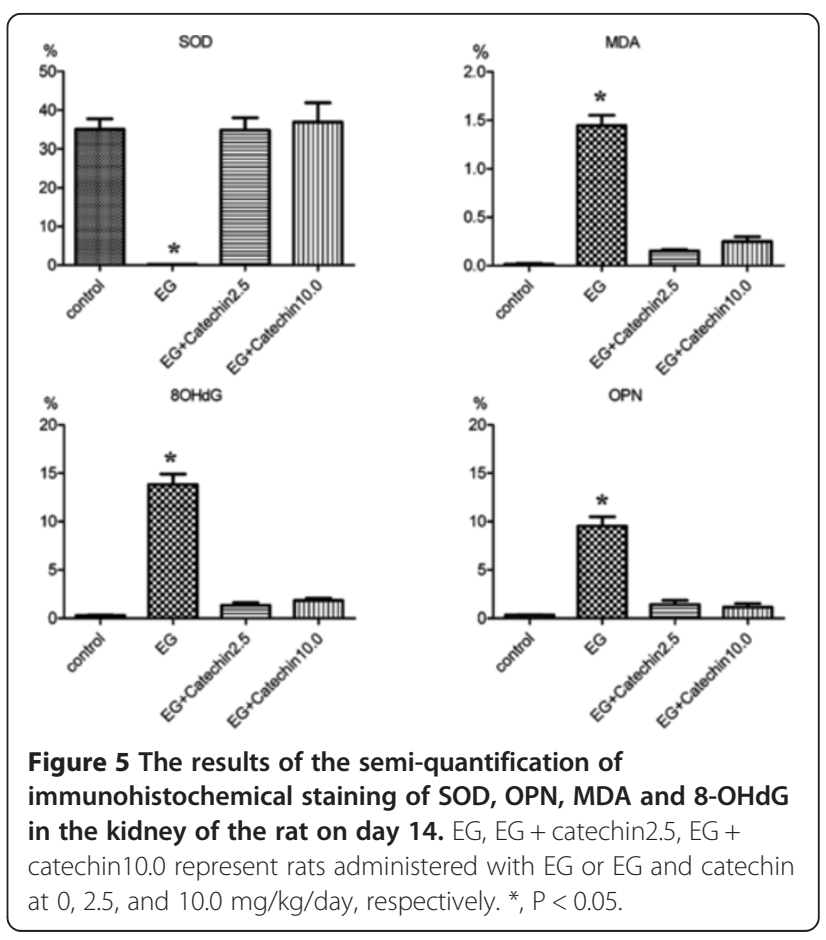



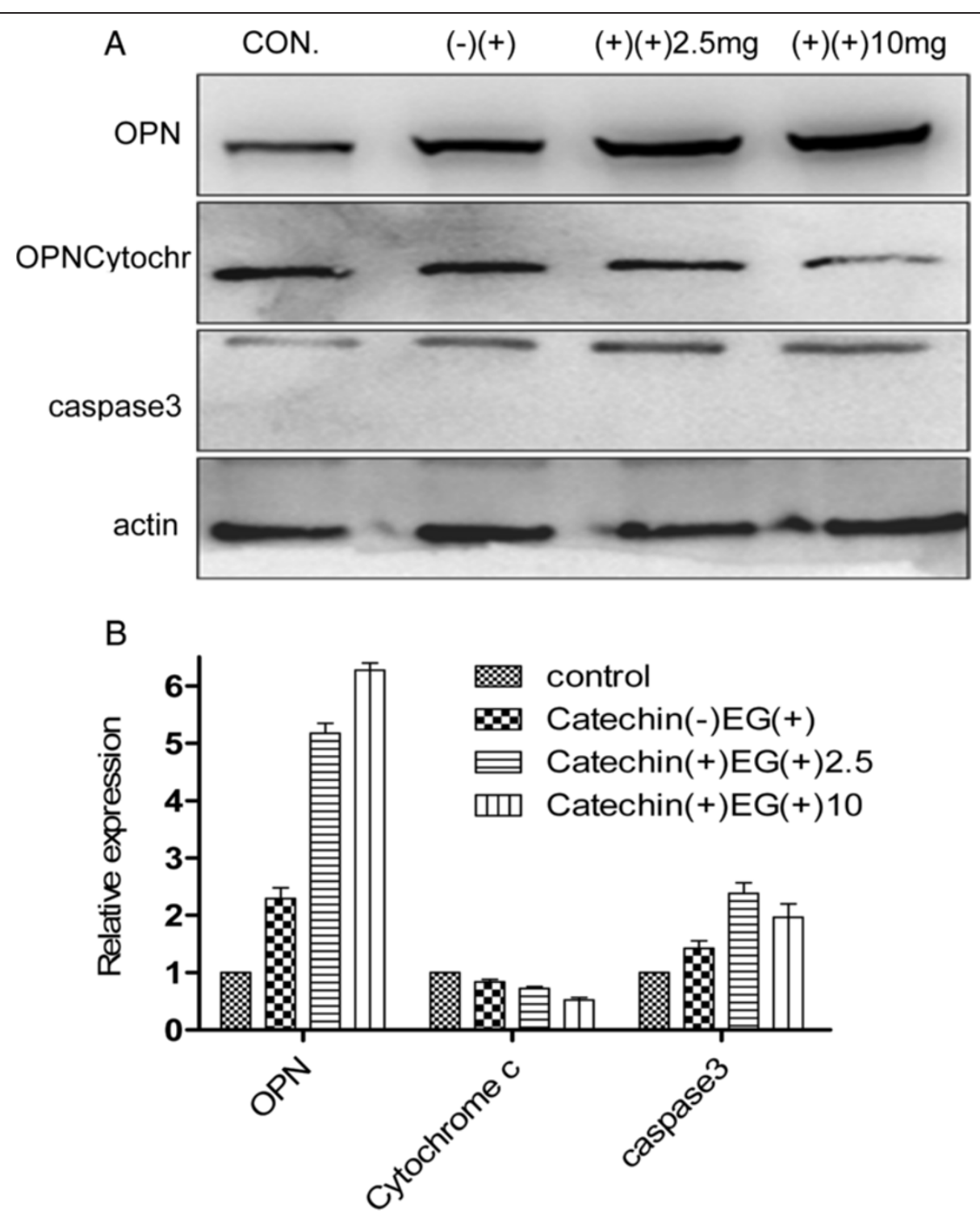

Figure 6 The expression changes of OPN, cytochrome $\mathrm{c}$ and cleaved caspase 3 were detected by western bolting on day 14 (A). The relative expression values of OPN, cytochrome $\mathrm{c}$ and cleaved caspase 3 were compared (B). EG, EG + catechin2.5, EG + catechin10.0 represent rats administered with $E G$ or $E G$ and catechin at $0,2.5$, and $10.0 \mathrm{mg} / \mathrm{kg} /$ day, respectively.

\section{Ultrastructural findings of kidneys exposed to EG in the} control and crystal-model rat

The renal tubules were circular, microvilli were evident in the lumen, and mitochondria were located around the nuclei in the control group (Figure 7).

In contrast, renal tubules of the EG group were thin with flattened tubular cells, the lumen of the renal tubule was expanded, microvilli were barely recognizable, and crystals were present in the lumen (Figure 7). Swollen mitochondria resembling fat droplets around the nuclei had an indistinct, discontinuous, and partly collapsed double membrane. However, the renal tubules of the EG + catechin (EG + catechin 2.5, and EG + catechin 10.0) groups were circular and microvilli were detected in the lumen; they were longer than those in the EG group, and the layer was thicker, but slightly shorter than that in the control group. The mitochondria had a regular internal structure with a continuous double membrane, similar to the mitochondria in the control group.

\section{Discussion}

Tea catechins, a subclass of compounds in the flavonoid family, have been found to have several biologically beneficial properties including antioxidative effects $[29,30]$. Flavonoids leading to cytoprotective effects against oxidative stress. Our findings, taken together with other observations [27,30-32], indicate that catechin demonstrates 


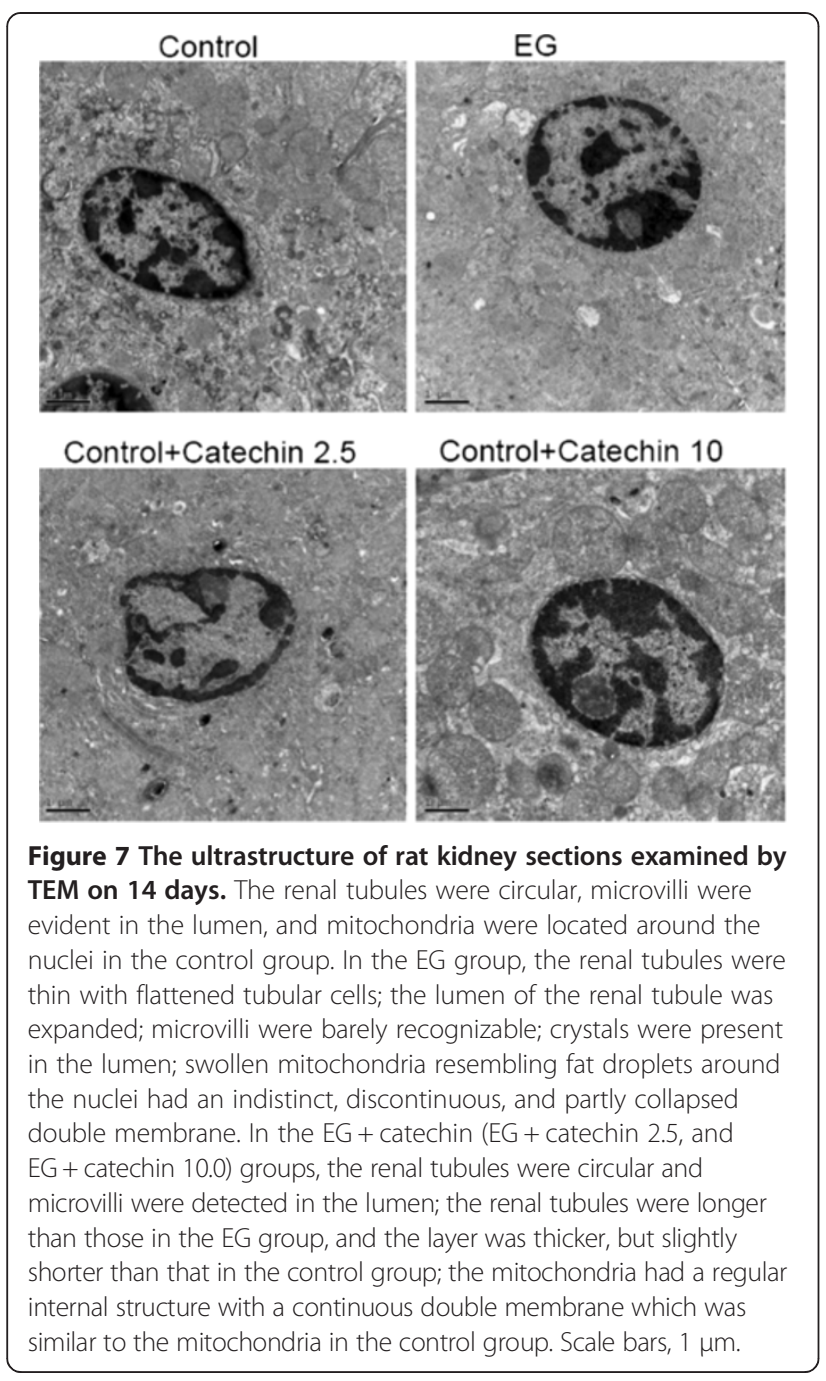

renoprotective abilities in several models of renal disease, especially nephrolithic nephropathy. The experiments indicate that catechins can attenuate functional and immunohistochemical changes in the renal proximal tubular cell line NRK-52E treated with COM and kidneys of EG induced nephrolithic rats.

In our in vitro study, catechin attenuated the changes of mitochondrial membrane potential, and normalized expression of SOD, 4-HNE, cytochrome c, and cleaved caspase 3 in the renal proximal tubular cell line NRK$52 \mathrm{E}$ treated with COM.

The disappearance of TMRE in NRK-52E cells indicated mitochondrial collapse through depolarization of the mitochondrial membrane. Disappearance of TMRE was gradual after exposure to COM crystals. COM crystals stimulate renal tubular cells to generate superoxide $(\mathrm{O} 2 \bullet-)$ via NADPH oxidase [33]. Furthermore, O2•leads to MPTP opening, which is considered to induce mitochondrial collapse [34]. The opening of the mPTP changes the $\Delta \psi \mathrm{m}$, which can be monitored using TMRE, a fluorescent probe that accumulates in polarized mitochondria and is released upon their depolarization. As catechin is a scavenger of free radicals or reactive oxygen species [35], it may attenuate the superoxide released by NADPH oxidase, and leads to normalize potential of the mitochondrial membrane.

Decreased superoxide dismutase and increased 4hydroxynonenal are often used as indexes of oxidative stress and cell injury. The generation of reactive oxygen species have been found to increase after the COM treatment in other studies $[1,36]$. The increase of antioxidant enzymes (SOD) and lipid peroxidation products (4-HNE) is likely a result of higher level of oxidative stress [37]. Binding of the released cytochrome c to cytosolic apoptosis protease activating factor 1 activates caspase 9 and caspase 3, which results in the induction of apoptosis. During this process, ROS are released from the intramembrane compartment into the cytosol, which further injures renal tubular cells. In our study, the increased expression of cytosolic cytochrome $\mathrm{c}$ and cleaved caspase 3 indicated that mitochondrial collapse and cell apoptosis could be induced by COM crystals.

In the in vivo study, oxidative stress was evaluated by SOD, MDA, and 8-OHdG expression in rats with EG induced renal calcium crystallization, which prevented by catechin. Oxalate and calcium oxalate $(\mathrm{CaOx})$ crystals are injurious to renal epithelial cells [38]. For monitoring DNA damage, 8-OHdG are the general marker [39], whereas MDA is examined for lipid peroxidation [40]. Our results showed that, mitochondria in the EG + catechin groups showed a regular internal structure with a continuous double membrane similar to that of mitochondria in the control group, while mitochondria in EG group showed an indistinct, discontinuous, and partly collapsed double membrane. This indicated that catechin prevented mitochondrial collapse, which induced by EG.

In the in rats with EG induced renal calcium crystallization, similar to the observation in NRK-52E cells, we also found the increase of cytochrome c release and the activation of caspase 3, which leads to the apoptosis or necrosis. These lipids disrupt mitochondrial function by increasing ROS, decreasing mitochondrial membrane potential, and increasing mitochondrial permeability [41]. Moreover, calcium oxalate $(\mathrm{CaOx})$ kidney stones are formed attached to Randall's plaques, which is the subepithelial deposits on renal papillary surfaces and triggered by reactive oxygen species [12].

As ROS plays an important role in the process of the development of the nephrolithiasis, antioxidant therapy has been described. In the previous studies, they found that vitamin $\mathrm{E}$ administration has been shown to prevent calcium oxalate precipitation in the rat kidney and decreased urinary oxalate excretion in patients with kidney 
stones [36]. It also restored antioxidant levels in the blood and decreased the urinary excretion of oxalate and calcium in patients who underwent surgical stone removal [42]. A previous study of antioxidant enzyme levels in rats with stone formation showed that almost all antioxidant enzyme activities were attenuated except that of catalase [43]. In agreement with previous studies, our results confirmed and extended the observation that the oxidative stress was greatly reduced by catechin treatment, which is an antioxidant component of green tea.

The expression of OPN was evenly and densely distributed throughout renal tubular cells of whole kidneys in the EG group. While in the control group and in the EG + catechin groups, the expression of OPN was barely detectable or localized to limited renal tubular cells. OPN, which identified as a major component of stone matrix protein, its expression was remarkably increased in the renal tubular cells of stone-forming rats $[44,45]$. Some studies suggested that OPN is an inhibitor of abnormal calcification in rat kidneys [46,47]. However, other studies suggested that OPN plays a role in stimulating the deposition and adhesion of crystals to cells in the early stages of crystallization. It is showed that calcium oxalate monohydrate crystal coating with OPN is correlated with increased adhesion tendency $[48,49]$. It is also reported that the kidney crystal deposition is decreased in OPN-deficient mice compared to crystal deposition in wild-type mice [50].

\section{Conclusions}

In conclusion, the results of our study have showed that catechin have preventive effects on renal calcium crystallization both in vivo and in vitro. However, the specific molecular mechanisms of catechin in renal calcium crystallization need to be further studied.

\section{Competing interests}

The authors declare that they have no competing of interests.

\section{Authors' contributions}

$\mathrm{J}-\mathrm{HZ}$ mainly contributed to the preparation of the manuscript and carried out the study described above. WZ, ML, Y-FX collected the data, and Y-FX reviewed the manuscript. All authors read and approved the final manuscript.

Received: 20 March 2013 Accepted: 28 August 2013

Published: 17 September 2013

\section{References}

1. Byer K, Khan SR: Citrate provides protection against oxalate and calcium oxalate crystal induced oxidative damage to renal epithelium. J Urol 2005, 173:640-646.

2. Goodman HO, Brommage R, Assimos DG, Holmes RP: Genes in idiopathic calcium oxalate stone disease. World J Urol 1997, 15:186-194.

3. Vezzoli G, Terranegra A, Rainone F, Arcidiacono T, Cozzolino M, Aloia A, Dogliotti E, Cusi D, Soldati L: Calcium-sensing receptor and calcium kidney stones. J Trans/ Med 2011, 9:201.

4. Khan SR: Role of renal epithelial cells in the initiation of calcium oxalate stones. Nephron Exp Nephrol 2004, 98:e55-e60.
5. Thamilselvan S, Byer K, Hackett RL, Khan SR: Free radical scavengers, catalase and superoxide dismutase provide protection from oxalateassociated injury to LLC-PK1 and MDCK cells. J Urol 2000, 164:224-229.

6. Kohjimoto Y, Kennington L, Scheid CR, Honeyman TW: Role of phospholipase A2 in the cytotoxic effects of oxalate in cultured renal epithelial cells. Kidney Int 1999, 56:1432-1441.

7. Umekawa T, Byer K, Uemura H, Khan SR: Diphenyleneiodium (DPI) reduces oxalate ion- and calcium oxalate monohydrate and brushite crystalinduced upregulation of MCP-1 in NRK 52E cells. Nephrol Dial Transplant 2005, 20:870-878.

8. van de Water B, Zoeteweij JP, de Bont HJ, Mulder GJ, Nagelkerke JF: Role of mitochondrial $\mathrm{Ca} 2+$ in the oxidative stress-induced dissipation of the mitochondrial membrane potential. Studies in isolated proximal tubular cells using the nephrotoxin 1,2-dichlorovinyl-L-cysteine. J Biol Chem 1994, 269:14546-14552.

9. Kawai Y, Nakao T, Kunimura N, Kohda Y, Gemba M: Relationship of intracellular calcium and oxygen radicals to Cisplatin-related renal cell injury. J Pharmacol Sci 2006, 100:65-72.

10. Khan SR: Crystal-induced inflammation of the kidneys: results from human studies, animal models, and tissue-culture studies. Clin Exp Nephrol 2004, 8:75-88.

11. Nakamoto K, Takayama F, Mankura M, Hidaka Y, Egashira T, Ogino T, Kawasaki H, Mori A: Beneficial effects of fermented green tea extract in a rat model of non-alcoholic steatohepatitis. J Clin Biochem Nutr 2009, 44:239-246.

12. Khan SR: Reactive oxygen species as the molecular modulators of calcium oxalate kidney stone formation: evidence from clinical and experimental investigations. J Urol 2012, 189:83-811.

13. Kawabata T, Ma Y, Yamador I, Okada S: Iron-induced apoptosis in mouse renal proximal tubules after an injection of a renal carcinogen, iron-nitrilotriacetate. Carcinogenesis 1997, 18:1389-1394.

14. El-Sharaky AS, Newairy AA, Badreldeen MM, Eweda SM, Sheweita SA: Protective role of selenium against renal toxicity induced by cadmium in rats. Toxicology 2007, 235:185-193.

15. Poovala VS, Kanji VK, Tachikawa H, Salahudeen AK: Role of oxidant stress and antioxidant protection in acephate-induced renal tubular cytotoxicity. Toxicol Sci 1998, 46:403-409.

16. Wang C, Salahudeen AK: Cyclosporine nephrotoxicity: attenuation by an antioxidant-inhibitor of lipid peroxidation in vitro and in vivo. Transplantation 1994, 58:940-946.

17. Salahudeen A, Poovala V, Parry W, Pande R, Kanji V, Ansari N, Morrow J, Roberts J 2nd: Cisplatin induces $\mathrm{N}$-acetyl cysteine suppressible F2-isoprostane production and injury in renal tubular epithelial cells. J Am Soc Nephrol 1998, 9:1448-1455.

18. Baliga R, Ueda N, Walker PD, Shah SV: Oxidant mechanisms in toxic acute renal failure. Am J Kidney Dis 1997, 29:465-477.

19. Servais H, Ortiz A, Devuyst O, Denamur S, Tulkens PM, Mingeot-Leclercq MP: Renal cell apoptosis induced by nephrotoxic drugs: cellular and molecular mechanisms and potential approaches to modulation. Apoptosis 2008, 13:11-32.

20. Kaushal GP, Basnakian AG, Shah SV: Apoptotic pathways in ischemic acute renal failure. Kidney Int 2004, 66:500-506.

21. Brooks C, Wei Q, Cho SG, Dong Z: Regulation of mitochondrial dynamics in acute kidney injury in cell culture and rodent models. J Clin Invest 2009, 119:1275-1285.

22. Porter AG, Janicke RU: Emerging roles of caspase-3 in apoptosis. Cell Death Differ 1999, 6:99-104.

23. Salvesen GS: Caspases: opening the boxes and interpreting the arrows. Cell Death Differ 2002, 9:3-5.

24. Ghavami S, Hashemi M, Ande SR, Yeganeh B, Xiao W, Eshraghi M, Bus CJ, Kadkhoda K, Wiechec E, Halayko AJ, Los M: Apoptosis and cancer: mutations within caspase genes. J Med Genet 2009, 46:497-510

25. Katunuma N, Matsui A, Le QT, Utsumi K, Salvesen G, Ohashi A: Novel procaspase-3 activating cascade mediated by lysoapoptases and its biological significances in apoptosis. Adv Enzyme Regul 2001, 41:237-250.

26. Li P, Nijhawan D, Wang X: Mitochondrial activation of apoptosis. Cell 2004, 116:S57-S59. 52 p following S59.

27. Cabrera C, Artacho R, Gimenez R: Beneficial effects of green tea-a review. J Am Coll Nutr 2006, 25:79-99. 
28. Higdon JV, Frei B: Tea catechins and polyphenols: health effects, metabolism, and antioxidant functions. Crit Rev Food Sci Nutr 2003, 43:89-143.

29. Chander V, Singh D, Chopra K: Catechin, a natural antioxidant protects against rhabdomyolysis-induced myoglobinuric acute renal failure. Pharmacol Res 2003, 48:503-509.

30. Hase M, Babazono T, Karibe S, Kinae N, Iwamoto Y: Renoprotective effects of tea catechin in streptozotocin- induced diabetic rats. Int Urol Nephrol 2006, 38:693-699.

31. Chennasamudram SP, Kudugunti S, Boreddy PR, Moridani MY, Vasylyeva TL: Renoprotective effects of (+)-catechin in streptozotocin-induced diabetic rat model. Nutr Res 2012, 32:347-356.

32. Jeong BC, Kim BS, Kim Jl, Kim HH: Effects of green tea on urinary stone formation: an in vivo and in vitro study. J Endourol 2006, 20:356-361.

33. Umekawa T, Tsuji H, Uemura H, Khan SR: Superoxide from NADPH oxidase as second messenger for the expression of osteopontin and monocyte chemoattractant protein-1 in renal epithelial cells exposed to calcium oxalate crystals. BJU Int 2009, 104:115-120.

34. Baines CP: The molecular composition of the mitochondrial permeability transition pore. J Mol Cell Cardiol 2009, 46:850-857.

35. Singh D, Chander V, Chopra K: Protective effect of catechin on ischemia-reperfusion-induced renal injury in rats. Pharmacol Rep 2005, 57:70-76.

36. Selvam R: Calcium oxalate stone disease: role of lipid peroxidation and antioxidants. Urol Res 2002, 30:35-47.

37. Thamilselvan S, Hackett RL, Khan SR: Lipid peroxidation in ethylene glycol induced hyperoxaluria and calcium oxalate nephrolithiasis. J Urol 1997, 157:1059-1063.

38. Khan SR, Thamilselvan S: Nephrolithiasis: a consequence of renal epithelial cell exposure to oxalate and calcium oxalate crystals. Mol Urol 2000, 4:305-312.

39. Niimi $K$, Yasui T, Hirose M, Hamamoto $S$, Itoh $Y$, Okada A, Kubota $Y$, Kojima Y, Tozawa K, Sasaki S, et al: Mitochondrial permeability transition pore opening induces the initial process of renal calcium crystallization Free Radic Biol Med 2012, 52:1207-1217.

40. Draper $\mathrm{HH}$, Hadley M: Malondialdehyde determination as index of lipid peroxidation. Methods Enzymol 1990, 186:421-431.

41. Jonassen JA, Cao LC, Honeyman T, Scheid CR: Mechanisms mediating oxalate-induced alterations in renal cell functions. Crit Rev Eukaryot Gene Expr 2003, 13:55-72.

42. Sumitra K, Pragasam V, Sakthivel $R$, Kalaiselvi $P$, Varalakshmi $P$ : Beneficial effect of vitamin $E$ supplementation on the biochemical and kinetic properties of Tamm-Horsfall glycoprotein in hypertensive and hyperoxaluric patients. Nephrol Dial Transplant 2005, 20:1407-1415.

43. Huang HS, Ma MC, Chen J, Chen CF: Changes in the oxidant-antioxidant balance in the kidney of rats with nephrolithiasis induced by ethylene glycol. J Urol 2002, 167:2584-2593.

44. Kohri K, Nomura S, Kitamura Y, Nagata T, Yoshioka K, Iguchi M, Yamate T, Umekawa T, Suzuki $Y$, Sinohara $H$, et al: Structure and expression of the mRNA encoding urinary stone protein (osteopontin). J Biol Chem 1993, 268:15180-15184

45. Kohri K, Suzuki Y, Yoshida K, Yamamoto K, Amasaki N, Yamate T, Umekawa T, Iguchi M, Sinohara $H$, Kurita T: Molecular cloning and sequencing of cDNA encoding urinary stone protein, which is identical to osteopontin. Biochem Biophys Res Commun 1992, 184:859-864.

46. Wesson JA, Johnson RJ, Mazzali M, Beshensky AM, Stietz S, Giachelli C, Liaw L, Alpers CE, Couser WG, Kleinman JG, Hughes J: Osteopontin is a critical inhibitor of calcium oxalate crystal formation and retention in renal tubules. J Am Soc Nephrol 2003, 14:139-147.

47. Steitz SA, Speer MY, McKee MD, Liaw L, Almeida M, Yang H, Giachelli CM: Osteopontin inhibits mineral deposition and promotes regression of ectopic calcification. Am J Pathol 2002, 161:2035-2046.

48. Yamate $T$, Kohri $K$, Umekawa $T$, Iguchi M, Kurita $T$ : Osteopontin antisense oligonucleotide inhibits adhesion of calcium oxalate crystals in Madin-Darby canine kidney cell. J Urol 1998, 160:1506-1512
49. Kumar V, Penade la Vega L, Farell G, Lieske JC: Urinary macromolecular inhibition of crystal adhesion to renal epithelial cells is impaired in male stone formers. Kidney Int 2005, 68:1784-1792.

50. Okada A, Nomura S, Saeki Y, Higashibata Y, Hamamoto S, Hirose M, Itoh Y, Yasui T, Tozawa K, Kohri K: Morphological conversion of calcium oxalate crystals into stones is regulated by osteopontin in mouse kidney. J Bone Miner Res 2008, 23:1629-1637.

doi:10.1186/1472-6882-13-228

Cite this article as: Zhai et al:: Catechin prevents the calcium oxalate monohydrate induced renal calcium crystallization in NRK-52E cells and the ethylene glycol induced renal stone formation in rat. BMC

Complementary and Alternative Medicine 2013 13:228.

\section{Submit your next manuscript to BioMed Central and take full advantage of:}

- Convenient online submission

- Thorough peer review

- No space constraints or color figure charges

- Immediate publication on acceptance

- Inclusion in PubMed, CAS, Scopus and Google Scholar

- Research which is freely available for redistribution 